\title{
Spray pyrolytically grown NiAlOx cermets for solar thermal selective absorbers: spectral properties and thermal stability
}

\author{
A BAGHERI KHATIBANI ${ }^{1, *}$ and S M ROZATI ${ }^{2}$ \\ ${ }^{1}$ Nano Research Lab, Lahijan Branch, Islamic Azad University, P.O. Box 1616, Lahijan, Iran \\ ${ }^{2}$ Physics Department, Faculty of Science, University of Guilan, Rasht 41335, Iran
}

MS received 6 August 2015; accepted 5 October 2015

\begin{abstract}
After deposition of NiAlOx thin films on stainless-steel substrates by the spray pyrolysis technique, various properties of the films were investigated using Fourier transform infrared spectroscopy, UV-visible reflectance spectrophotometry, energy-dispersive X-ray spectroscopy (EDX), X-ray diffraction (XRD) and scanning electron microscopy (SEM). Optical quantities were determined using reflectance spectra in the relevant spectrum region. At first the optimal substrate temperature was selected and then different nickel to aluminium ratios were examined to find the efficient solar absorber. The SEM revealed changes in morphology due to different molar ratios. The XRD of the selected sample showed a mixture of nickel and nickel oxide phases with the strong presence of substrate peaks and without the presence of alumina phase while in the EDX test the peaks corresponding to $\mathrm{O}, \mathrm{Al}$ and $\mathrm{Ni}$ appeared. Long-term thermal stability study was performed by means of performance criterion concept.
\end{abstract}

Keywords. Spectral selectivity; absorber-reflector tandem; NiAlOx thin films; spray pyrolysis; optical properties.

\section{Introduction}

The sun, one of renewable sources, is the vast majority of energy used by people on the earth. The direct use of solar energy may make significant contributions to mankind's future energy. The sun's energy is environmental friendly and can be converted to heat and electricity. Hence to harness this inexhaustible energy, solar-thermal systems are the most important candidates [1]. Conversion of solar radiation into useful heat involves the optical properties of solids, modification of micro- or nanostructures and optimization of material characteristics, and preparation techniques.

Nowadays, between various mechanisms and categorizations of absorbing media like as intrinsic selective absorber, multilayer absorber, quantum size effect, surface texturing, heat mirrors and so on, one of the most common type absorbers is an absorber-reflector tandem. It is obtained by the combination of two surfaces: the first one is the front surface of the coating with high absorptance in the solar wavelength range $(0.3-2.5 \mu \mathrm{m})$ and low emittance (due to high transmittance) in the infrared wavelength range $(2.5-50 \mu \mathrm{m})$ and the second is the surface beneath with low emittance (due to high reflectance) in the same infrared wavelength range [2]. However, there is a trade-off between a highly absorbing coating and one with low emittance. Highly absorbing coatings appear rough, porous, and absorb solar energy; coatings with low emittance are very smooth, dense, highly reflective and mirror-like to thermal energy [3]. The design principle of the layer structure in tandem absorber is to obtain a very

\footnotetext{
*Author for correspondence (bagherikhatibani@gmail.com)
}

high solar absorptance in combination with an extremely low thermal emittance. It is often designed as in the present case based on two optical principles: (i) high absorptance in metal particles for wavelengths that are much longer than the particle dimension and (ii) optical interference in thin films [2].

Cermets as a selective absorber are composed of metal particles embedded in a ceramic host. The ceramic matrix usually consists of oxide, boride, nitride, carbide or oxynitride components and a crystalline metallic phase is assumed to be embedded in this matrix. A cermet should have ceramic characteristics in the visible spectrum and metallic properties in the infrared. The coating thickness, constituents and metal volume fraction in the matrix, as well as particle size, shape and orientation can affect how strongly the ceramic or metallic characteristics are expressed across the solar and infrared spectra. Thicker coatings and smaller particle sizes are beneficial for high absorptance in the visible range. With an increase in the particle radius, there is a shift of the visible absorption and scattering, resulting in lower absorption. The thermal emittance in the infrared can be decreased by decreasing the coating thickness and increasing the metallic concentration $[4,5]$. Such composite meta-structures allow merging specific properties of both compounds, such as highthermal stability, corrosion resistance and hardness of the ceramic, on one hand, electrical conductivity and ductility of the metal, on the other hand. Indeed these coatings absorb efficiently the solar radiation while avoiding over warming of the absorber material [6].

The process of the state-of-the-art cermet-based solar absorbers have been reviewed by Cao et al [5]. They have 
investigated the preparation techniques, materials and performance of cermet-based spectrally selective absorbers [5].

Ideally, solar selective absorbers should be perfect absorbers over the solar spectrum and perfect reflectors in the thermal infrared (IR). The latter is in order to avoid heat losses due to the emission of radiation from the surface according to Kirchhoff's law [7].

Spectral selectivity and characteristic cut-off wavelength (transition wavelength from low to high reflection) of composite absorbers depend on the volume fraction, particle concentration, shape and orientation of the particles, optical constants of the constituents and thickness of the composite coating which offers a high degree of flexibility to solar selectivity.

Solar selective absorbers can be formed by several techniques such as DC reactive magnetron sputtering [8], RF magnetron sputtering $[9,10]$, electrochemical approach $[11,12]$, spin coating [2,13], electroless plating [14], electrodeposition [15,16], chemical oxidation [17], cathodic arc evaporation $[18,19]$ and spray pyrolysis $[20,21]$.

$\mathrm{Al}_{2} \mathrm{O}_{3}$-based cermet coatings were first exploited in the late 1970s by Craighead [22] and Granqvist [23] and afterward were followed by other researchers with the same or different metal portion such as $\mathrm{Ni}-\mathrm{Al}_{2} \mathrm{O}_{3}$ [13,24], Mo$\mathrm{Al}_{2} \mathrm{O}_{3}$ [25,26] and $\mathrm{Co}-\mathrm{Al}_{2} \mathrm{O}_{3}$ [12], $\mathrm{Pt}-\mathrm{Al}_{2} \mathrm{O}_{3}$ [27], $\mathrm{Cr}-\mathrm{Al}_{2} \mathrm{O}_{3}$ [28], $\mathrm{Ag}-\mathrm{Al}_{2} \mathrm{O}_{3}$ [29], $\mathrm{AlNi}-\mathrm{Al}_{2} \mathrm{O}_{3}$ [30], $\mathrm{W}-\mathrm{Al}_{2} \mathrm{O}_{3}$ [31] and $\mathrm{Fe}-\mathrm{Al}_{2} \mathrm{O}_{3}$ [32].

At present, electrochemical deposition and sputtering are two main techniques used to prepare $\mathrm{Al}_{2} \mathrm{O}_{3}$-based cermet coatings [13] and there are few reports of fabrication of such structures by spray pyrolysis. Hence, in this article aluminabased coating (as an absorber) was deposited on stainless steel (as an IR-reflector) by the spray pyrolysis (SP) method to attain the desired purpose. On the other hand, the metallic substrate provides high IR reflectance and contributes a small portion of the absorption in the ultraviolet (UV) and visible regions.

\section{Materials and method}

Among the different methods for film deposition spray pyrolysis is suitable for the preparation of efficient and inexpensive thin films. They can be easily prepared using spray pyrolysis since it is very simple, low cost method over large area and does not require vacuum or exotic gas. In this method, fine droplets react on the heated substrate, owing to the pyrolytic decomposition of the solution. The hot substrate provides the thermal energy for the thermal decomposition and subsequent recombination of the constituent species [33]. Thus, the substrate temperature, carrier gas flow, substrate rotating speed, number of spraying sequences, spraying distance, solution flow rate and molarity play an important role in the formation of the structure of the films ranging from amorphous to crystalline.

The SP device is an experimental apparatus (SCS 90, made by Modern Technology Development Co., Iran), the optimized values are the nozzle-substrate distance $(H=34 \mathrm{~cm})$ and the carrier gas pressure (air, $p=1.5$ bar). The substrate rotation speed, nozzle aperture diameter are also fixed.

Briefly, $25 \mathrm{ml}$ aqueous alcoholic solutions of $\mathrm{AlCl}_{3}(98 \%$, Merck) and $\mathrm{NiCl}_{2} \cdot 6 \mathrm{H}_{2} \mathrm{O}(97 \%$, Chem-Lab) were used as precursors for the alumina and nickel mixture thin films in preparation. Deionized water (W) and absolute ethanol $\left(\mathrm{C}_{2} \mathrm{H}_{5} \mathrm{OH}, 99.9 \%\right.$, Merck) were used as solvents (water : ethanol $=1: 1$, in volumes). The precursor solutions had $0.25 \mathrm{~mol}^{-1}$ concentration and nickel content (mole percentage of nickel ions to total metallic ions) were altered as 10 , 20, 40, 60, 80 and 90\%. Finally, the solution was sprayed perpendicularly onto preheated stainless-steel (SS) substrates which were previously polished by soft sand papers and immersed in $\mathrm{H}_{2} \mathrm{SO}_{4} 20 \%$ solution for $24 \mathrm{~h}$ and then cleaned with acetone and dry air.

After the substrate was coated, it was heat treated in a nitrogen atmosphere $\left(21 \mathrm{~min}^{-1}\right)$ inside a quartz glass tube. The thin films were heated at a final temperature $550^{\circ} \mathrm{C}$ in duration of about $1 \mathrm{~h}$ to prevent or confine nickel oxidation as possible that has a destructive role in solar efficiency [11]. The preparation steps can be observed schematically in figure 1 .

To characterize the samples, reflectance was measured by a Perkin-Elmer Lambda $25 \mathrm{UV} /$ vis/NIR double-beam spectrophotometer equipped with an integrating sphere and a Fourier transform infrared (FTIR) reflectance spectrometer named Perkin-Elmer spectrum one. These data were used to

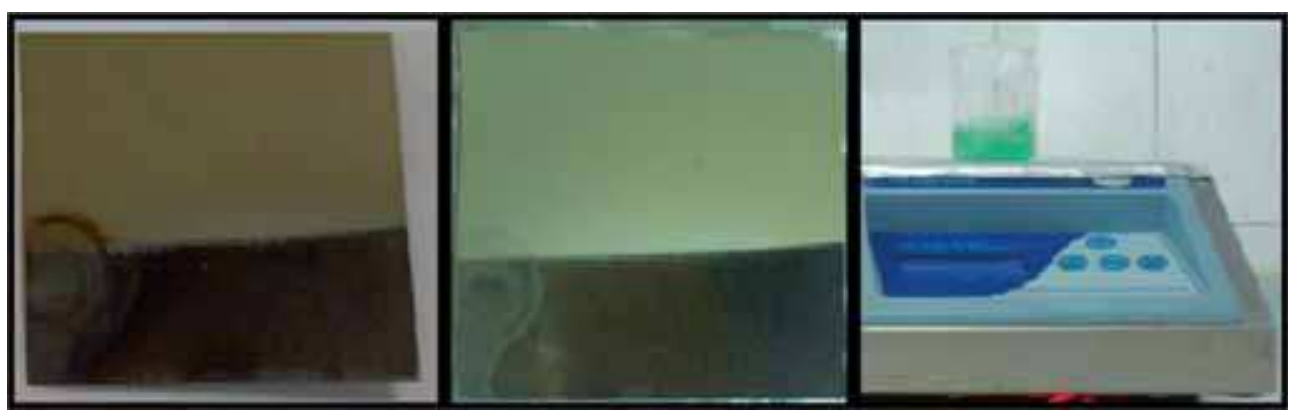

Figure 1. Schematic preparation steps of NiAlOx samples from right to left: stirring the precursor solution (right), deposition on SS substrate (middle) and thermal treatment (left). 
calculate the normal solar absorptance and the normal thermal emittance of the coatings. The composition of absorbing coating was determined by X-ray diffraction (XRD) using a X-ray diffractometer (PW1840-Diffractometer, Philips) with $\mathrm{CuK} \alpha(15 \mathrm{kV}, 30 \mathrm{~mA})$ radiation. The surface morphology of absorbing coating was observed with a scanning electron microscope (SEM) LEO 1455 vp. Energy-dispersive Xray spectroscopy (EDX) was also used for the elemental analysis.

\section{Results and discussion}

The optical properties of an absorbing coating are characterized by two parameters, i.e., normal solar absorptance, $\alpha_{\mathrm{s}}$, and normal thermal emittance, $\varepsilon_{\mathrm{t}}$, defined as follows:

$$
\begin{gathered}
\alpha_{\mathrm{s}}=\frac{\int_{0.3}^{2.5} I_{\mathrm{s}}(\lambda)(1-R(\lambda)) \mathrm{d} \lambda}{\int_{0.3}^{2.5} I_{\mathrm{s}}(\lambda) \mathrm{d} \lambda}, \\
\varepsilon_{\mathrm{t}}=\frac{\int_{2.5}^{25} I_{\mathrm{b}}(\lambda, T)(1-R(\lambda)) \mathrm{d} \lambda}{\int_{2.5}^{25} I_{\mathrm{b}}(\lambda, T) \mathrm{d} \lambda},
\end{gathered}
$$

where $I_{\mathrm{S}}(\lambda)$ is the solar spectral radiation of AM1.5 according to the ISO Standard 9845-1 (1992) [13] or its equivalent ASTM G173-03 Reference Spectrum (AM1.5) [34], $R(\lambda)$ is the measured reflectance at a specific wavelength $\lambda$ and $I_{\mathrm{b}}(\lambda, T)$ is the black-body spectral radiation. $T=373 \mathrm{~K}$ is used for calculating $\varepsilon_{\mathrm{t}}$.

As it is known, although alumina has absorbing properties by itself [35] but commonly it can be infiltrated with metal or/ and metal oxide particles for the preparation of a cermet [36].

At first, alumina thin films were prepared on stainless-steel substrates at optimized conditions according to our previous finding [35]. Figure 2 shows the reflectance spectra of the single alumina layer.

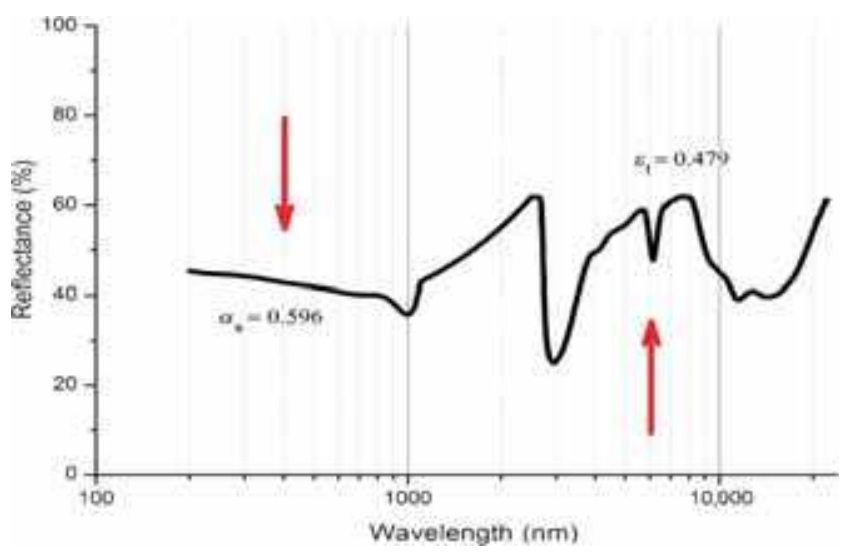

Figure 2. Reflectance spectra of the single alumina thin films.
Solar absorptance and thermal emmitance were calculated and its ratio was $S=1.242$. According to what is called solar selectivity and is usually used to evaluate the spectral properties of solar selective absorber coatings, this sample has spectral selectivity [37]. However, the reflectance should be decreased in the UV/vis/NIR region and increased in FIR region (red arrows) to enhance the solar selectivity as an acceptable solar absorber.

As a subsidiary argument, absorption bands in the recorded FTIR spectra can be discussed traditionally. In a general view, three major absorption bands are recognizable: 10,500-16,500 $\mathrm{nm}$ are assigned to amorphous aluminium oxide [38,39], 5500-7500 $\mathrm{nm}$ can be attributed to carboxylate groups, and 2600-3800 nm is caused by Al-OH bonds and its broadness suggests that hydrogen bonding has occurred [40]. One of the most important factors in decreasing the emmitance is to confine to the depth and breadth of $\mathrm{Al}-\mathrm{OH}$ bonds.

Later nickel salt is added to the precursor solution to attain a homogeneous aqueous precursor solution containing Aland $\mathrm{Ni}$-chlorides together.

Because of the variety of the deposition parameters and to find an optimal substrate temperature that has a key role in the SP technique, at first stage an intermediate nickel content solution (60 over 40, nickel to aluminium ratio) is chosen and various substrate temperatures ranging from 300 to $550^{\circ} \mathrm{C}$ is examined. The reflectance of the samples are shown in figure 3 and the relevant solar absorptance values are included in table 1 .

Despite the little difference between absorptance values, which show the impact of the presence of nickel on alumina property, but it appears the third sample is more worthy because of its highest value of solar absorptance. Therefore, $400^{\circ} \mathrm{C}$ was selected as an optimal substrate temperature.

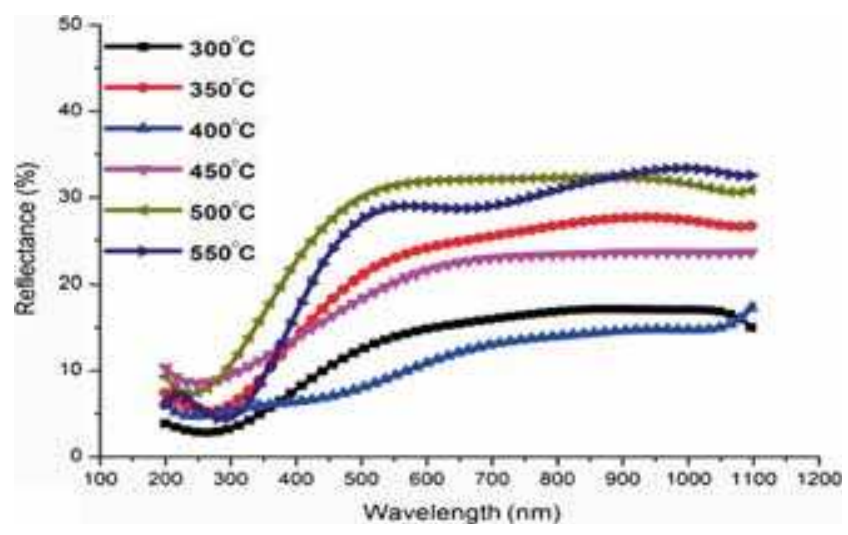

Figure 3. Reflectance spectra of the samples with identical nickel content (60/40) at different substrate temperatures.

Table 1. Solar absorptance at various substrate temperatures.

Substrate

temperature $\left({ }^{\circ} \mathrm{C}\right) \quad 300 \quad 350 \quad 400 \quad 450 \quad 500 \quad 550$

$\begin{array}{lllllll}\text { Solar absorptance } & 0.857 & 0.767 & 0.874 & 0.793 & 0.698 & 0.721\end{array}$ 


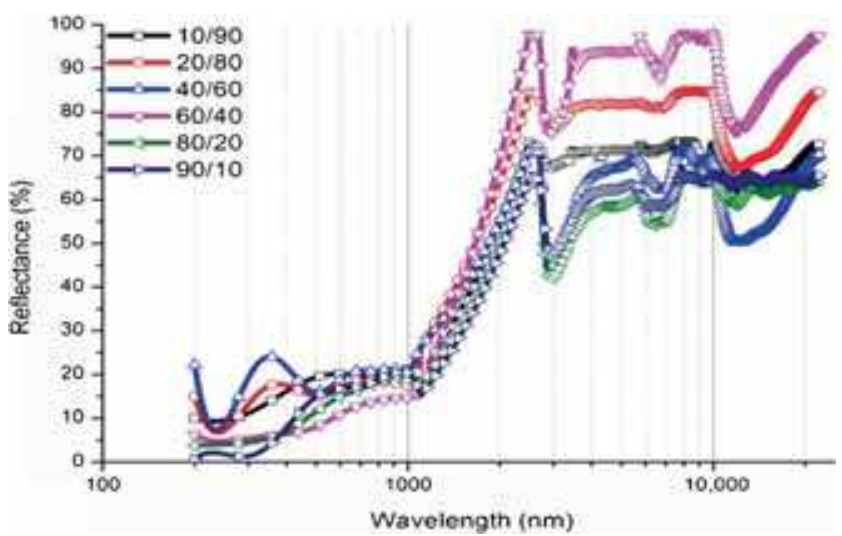

Figure 4. Reflectance spectra of the samples with different nickel contents at fixed substrate temperature.

Table 2. Solar absorptance and thermal emittance of various nickel to aluminium ratio at $400^{\circ} \mathrm{C}$ substrate temperatures.

\begin{tabular}{lccc}
\hline Nickel/aluminium & $\alpha_{\mathrm{s}}$ & $\varepsilon_{\mathrm{t}}$ & $S$ \\
\hline $10 / 90$ & 0.806 & 0.298 & 2.705 \\
$20 / 80$ & 0.826 & 0.196 & 4.214 \\
$40 / 60$ & 0.801 & 0.356 & 2.251 \\
$60 / 40$ & 0.887 & 0.083 & 10.69 \\
$80 / 20$ & 0.853 & 0.403 & 2.117 \\
$90 / 10$ & 0.839 & 0.379 & 2.214 \\
\hline
\end{tabular}

Then, the ratio of nickel content is altered to find more absorber thin film and to calculate solar absorptance and thermal emittance according to equations (1) and (2). The reflectance of the thin films in the range $200-20,000 \mathrm{~nm}$ is measured and presented in figure 4 . The relevant optical coefficients are summarized in table 2.

According to selectivity criterion, the sample S4 (60/40 nickel to aluminium) is significantly better than the others. Although there is not any limit to the selectivity value and it can be any number, but from a practical point of view, the higher the selectivity the better the result.

Since spectral selectivity and characteristic cut-off wavelength depend on several parameters as mentioned before, surface investigation of the films seems to be helpful. By using SEM surface and microstructure of the samples is presented in figure 5. Different morphologies can be observed ranging from continuous and homogeneous grains to accumulated ones with spherical or irregular shapes. Although a kind of porosity is also observable in the latter samples which may be the reason of better absorptance besides the more regular nanosized grains. However, it is not possible to distinguish nickel particles among alumina ones.

The composition of an optimum absorbing coating was investigated by XRD. Since, it is accepted that alumina in the temperature range below $600^{\circ} \mathrm{C}$ has an amorphous structure regardless of the deposition method [41], the related peaks are not expected to be observed.
As shown in figure 6 , the sharp peak at about $51^{\circ}$ is assigned to the diffraction of SS substrate (JCPDS no. 330397), while other broad diffraction peaks are of nickel (JCPDS no. 01-1260) and nickel oxide diffraction (JCPDS no. 01-1239). The relevant diffraction planes are marked into the diffraction curves. The fairly large broadening of the peak between $43^{\circ}$ and $44^{\circ}$, is resolved into two peaks at relative lower values of $43.34^{\circ}$ and $43.66^{\circ}$ by fitting with Gaussian distributions (figure 7). They are attributed to nickel oxide and stainless-steel diffraction peaks, respectively.

According to our previous results [33,35] about pure alumina in similar condition, due to heat treatment hole-like defects on the film surface are formed. These changes in morphologies themselves not only bring about the change of optical response to the incident light, but also play a significant role in atom diffusion by acting as the paths for infiltration of metal or/and metal oxide particles movement [42].

The crystallite sizes of nickel and nickel oxide were estimated from the related diffraction peaks using Scherrer's famous equation and were about $20 \mathrm{~nm}$, which fulfilled the particle size of absorbing films for solar applications [7]. The present results indicate that nickel ions can be reduced somewhat into nano-sized nickel particles during the heat-treatment process, but the oxidation also accompany by the process because of deposition method and environmental conditions. Meanwhile, as mentioned before, because of alumina amorphous characteristic in this substrate temperature region, there is not any relevant peak. For this, to ensure the formation of alumina in our thin films, IR spectra of the samples can be appealed (figures 2 and 4).

With a closer look, it seems there is a discrepancy between XRD and SEM results, but actually there would be no surprise, since by Scherrer's equation the crystallite size is calculated, whereas SEM shows the agglomeration, and single aggregate contains number of crystallites [43].

The quantitative analysis of the optimized sample was carried out by using energy-dispersive X-ray (EDX) analysis to study stoichiometry of nanostructured thin film. The results are shown in figure 8 and tabulated in table 3. The peaks corresponding to $\mathrm{O}, \mathrm{Al}$ and $\mathrm{Ni}$ were present in the EDX spectra. Oxygen abundance confirms that the chemical oxidation has a powerful role in the structure. The atomic ratio between $\mathrm{Al}$ and $\mathrm{Ni}$ was found to be 0.6, contrary to the initial value 1.5 . It seems $\mathrm{Al}$ and its oxide have a more active presence on the surface of the sample which is desirable preventing more oxidation of $\mathrm{Ni}$ particles through the structure, meanwhile works as an antireflection coating.

To obtain an idea about the thickness and investigate more optical parameters, another sample just like the optimized sample was prepared unless the substrate was changed and a glass substrate was replaced. After preparation steps, thickness, transmittance and reflectance measurements were carried out which are shown in figure 9. 

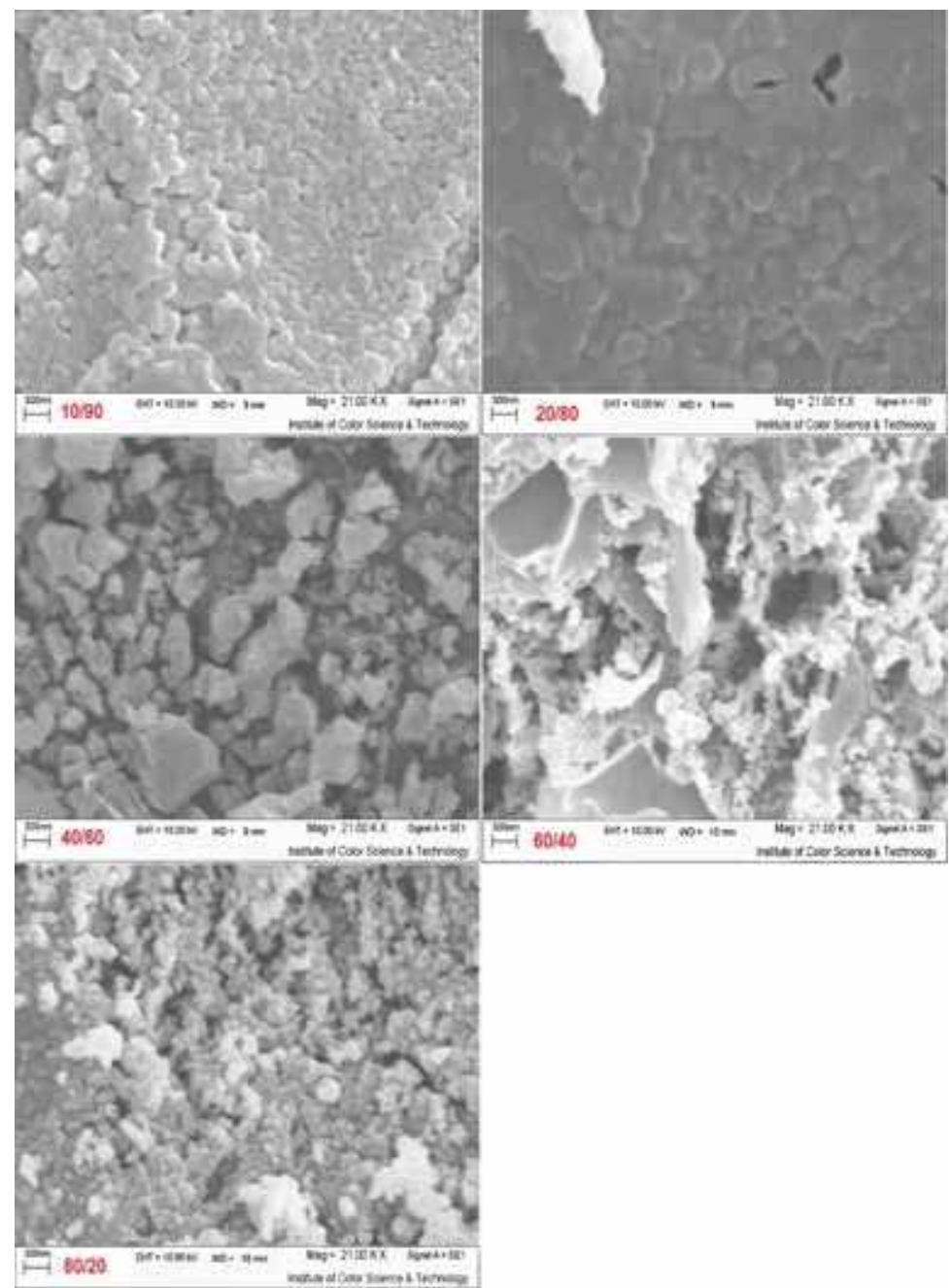

Figure 5. Surface morphology of the samples with different nickel contents at fixed substrate temperature.

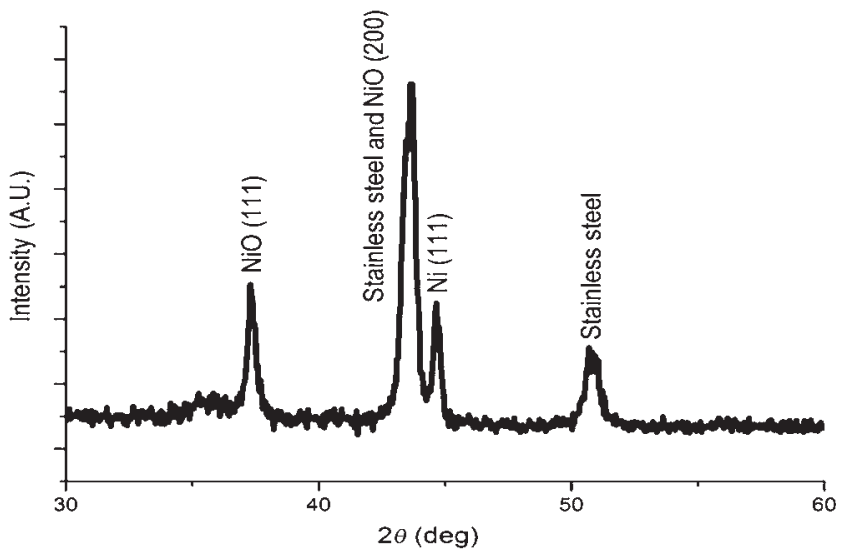

Figure 6. XRD patterns of the selected film.

Using these data and some optical relations, it is possible that refractive index and extinction coefficients of the film were estimated. These optical constants have a major role for choosing and improving the selectivity of solar absorber

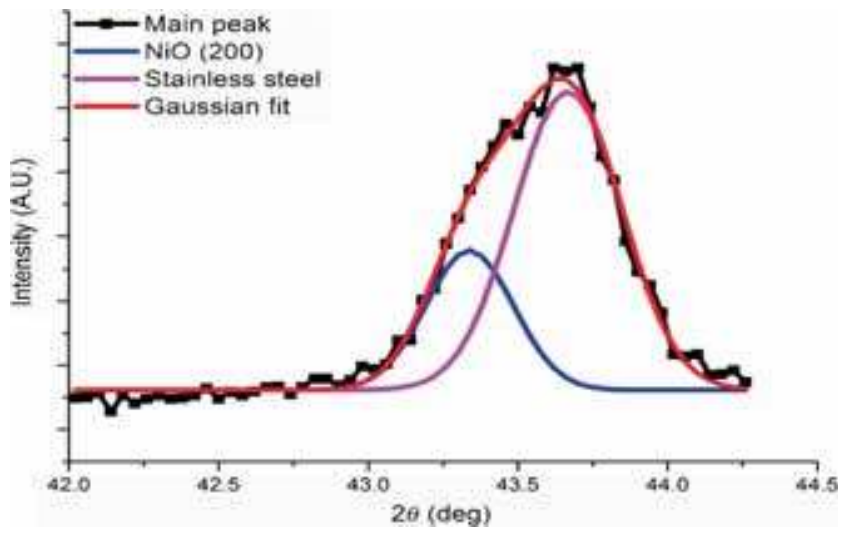

Figure 7. Deconvolution of XRD data into two peaks at $43.34^{\circ}$ and $43.66^{\circ}$, respectively.

coatings. Farooq has shown that higher refractive index composites lead to better selectivity and also it was noticed that a material with higher extinction coefficient may lead to higher solar absorptance [44]. 


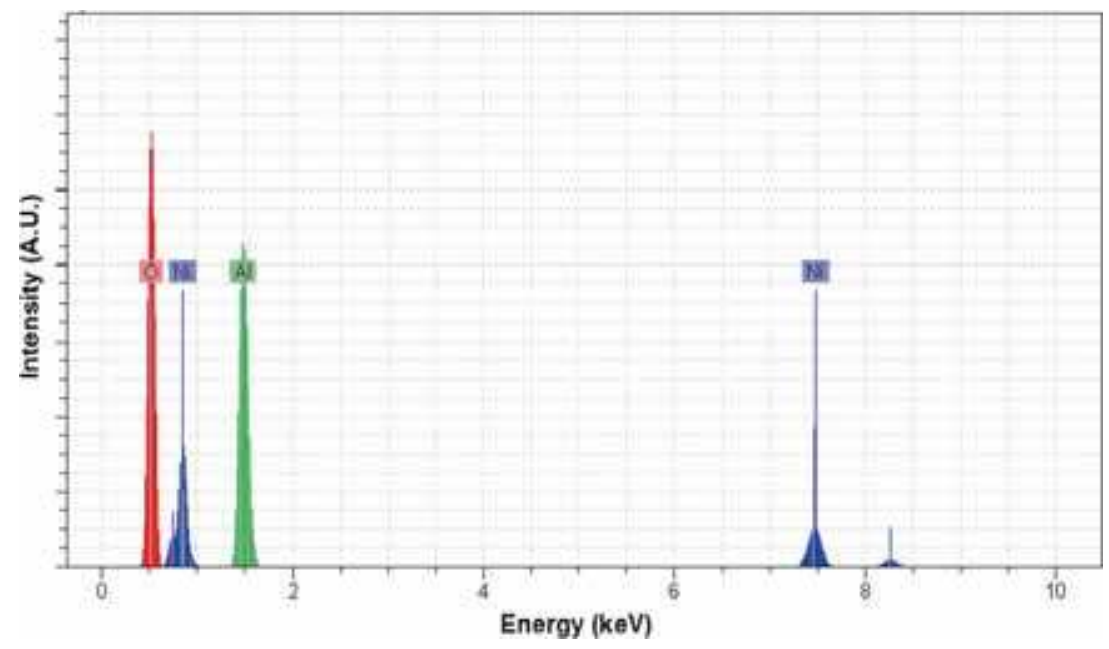

Figure 8. Energy-dispersive spectra (EDX) of the optimized thin film.

Table 3. Concentration of elements in optimized thin film.

\begin{tabular}{lcccc}
\hline Element & Series & $\begin{array}{c}\text { Unnormalized } \\
\text { concentration (wt\%) }\end{array}$ & $\begin{array}{c}\text { Normalized } \\
\text { concentration (wt\%) }\end{array}$ & $\begin{array}{c}\text { Atomic per cent } \\
\text { concentration (at\%) }\end{array}$ \\
\hline Oxygen & K series & 39.32 & 49.37 & 70.32 \\
Aluminium & K series & 17.48 & 21.95 & 18.54 \\
Nickel & K series & 22.84 & 28.67 & 11.13 \\
\hline
\end{tabular}

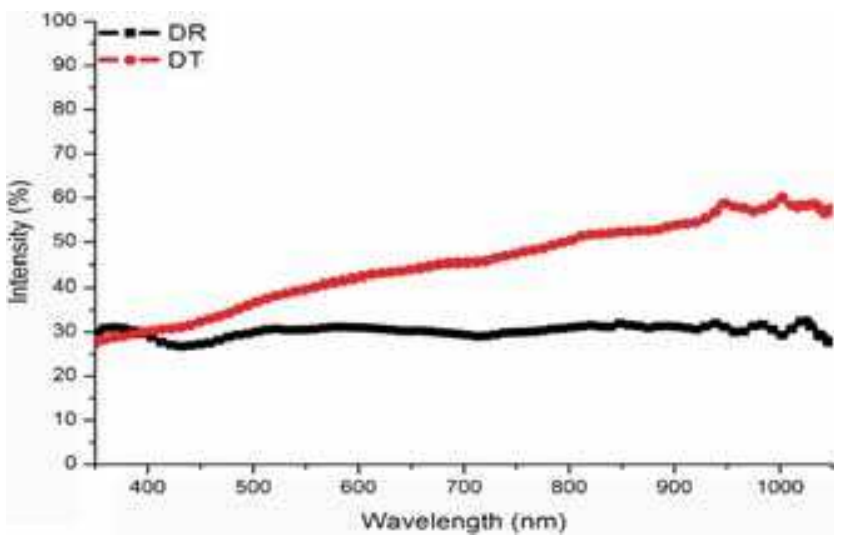

Figure 9. Transmittance and reflectance spectra for selected NiAl sample.

The absorption coefficient is given by [45]

$$
\alpha=\frac{1}{d} \ln \left(\frac{(1-R)^{2}}{T}\right),
$$

where $d, T$ and $R$ are the thickness, transmittance and reflectance of the film, respectively.

With familiar relation for extinction coefficient (i.e., $k=$ $\alpha \lambda / 4 \pi)$; it is a straightforward calculation. The result is plotted in figure 10 .

As the extinction coefficient of alumina in the solar spectrum is near to zero, then the solar absorptance can only

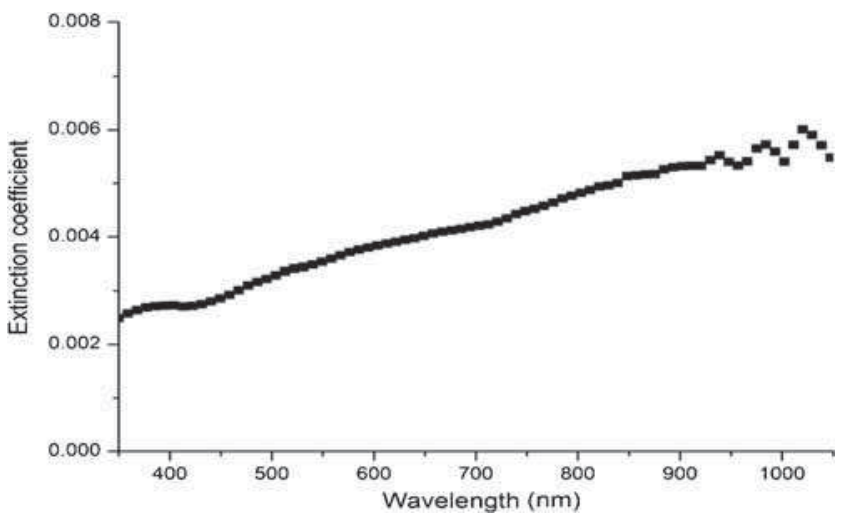

Figure 10. Variation of extinction coefficient $v s$. wavelength for selected film.

depend on the extinction coefficient of the metal component of the cermet [7].

Because of mismatch of environment (often air) and substrate (often a metal) optical constants and hence its negative effects on solar absorption, a selective absorber normally consist of thin films, sandwiched between the antireflection (AR) layer and a metallic substrate. A graded refractive index coating is recommended for this purpose and it should be designed with a continuously decreasing refractive index and an extinction coefficient from the substrate to the antireflection coating surface [46]. The ideal case is to have a refractive index $n=1$ and extinction coefficient, $k=0$ at the 
front surface in order to avoid refraction mismatch between air and the top coating. In reality, a graded multilayer (2-5 layers) composite can produce over $95 \%$ absorptance with a very low emittance. By proper choice of constituents, particle concentration, size, shape, orientation, layer thicknesses and refractive indices, the thin film destructive interference effect is in most cases used to enhance the solar absorptance. However, unity absorptance is almost impossible to attain in practice.

Although several layers can be stacked to enhance solar absorptance but based on Nejati's calculations, increasing the number of cermets does not improve the optical response of the selective coatings and that there is no strong dependence of cermet structure on the final optical properties. It can be concluded that the two-cermet-layer structure, because of the ease of fabrication, is the most suitable for a cermet solar selective absorber [7].

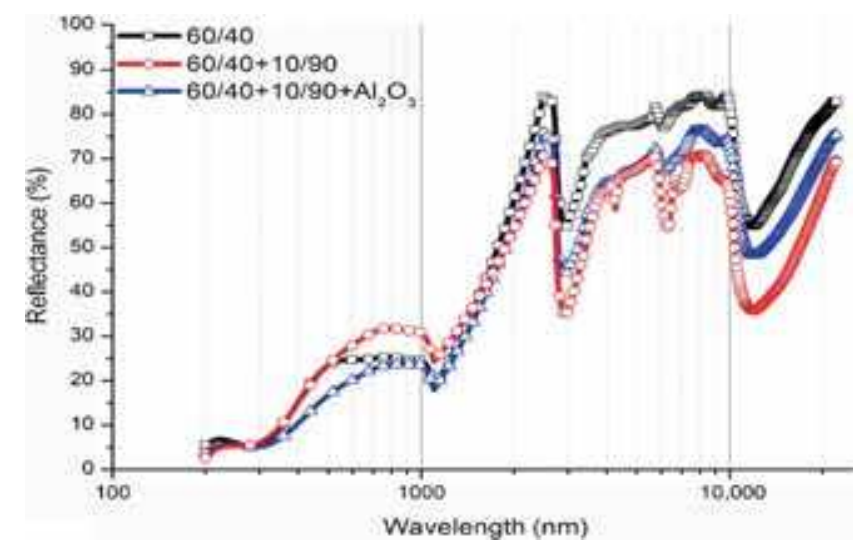

Figure 11. Multilayer structure composed of (60/40) nickel to aluminium (1st layer) and $(60 / 40+10 / 90)$ nickel to aluminium (1st and 2 nd layer) and $(60 / 40+10 / 90+$ alumina $)$ as a (1st, 2 nd and 3rd layer).
By computer modelling calculations, Zhang predicted a double cermet layer structure that has higher photo-thermal conversion efficiency than surfaces using a homogeneous cermet layer or a graded film structure [47]. Solar radiation is effectively absorbed internally and by phase interference in double-cermet solar coatings. Further, it is easier to deposit the double-cermet selective coating than graded-cermet layer selective surfaces. The typical coating structure from surface to substrate consists of an anti-reflection layer composed of a transparent ceramic material that enhances solar transmission, a low metal volume fraction (LMVF) cermet solar absorption layer, a high metal volume fraction (HMVF) cermet solar absorption layer, which forms interference absorption bilayer, and an IR-reflective metallic layer that decreases the IR emission [48].

According to above, a three-layer structure on SS substrate in three forms was prepared and the results were compared with figures 11-13 and tables 4-6. In all of the cases the first layer was optimized 60/40 nickel to aluminium sample but for second layer three forms were chosen to form LMVF structure. Generally speaking, a solar selective absorber due to selectivity criterion was acquired. It seems the first configuration is more appropriate than the others. But no better results were observed with the increase in the layers. It may be due to lack of thickness control in our deposition method. Total increase of solar absorption confirms the claim.

Thicker cermets are needed to reach the low reflectance in the visible region but thermal emittance strongly increases as the thickness of the cermet increases due to IR absorption. Reducing the thickness and increasing the metallic concentration in the same proportion can reduce emittance [48]. The optical properties of the cermets can be improved by using the optimum cermet thickness and particle diameter of the constituent.

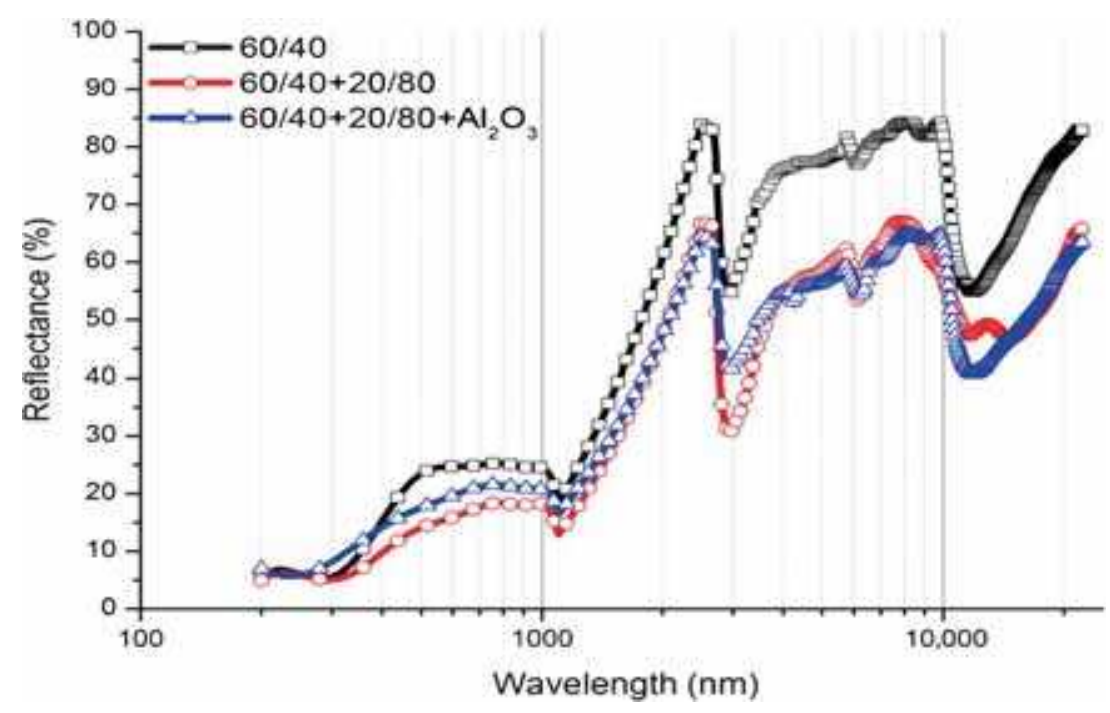

Figure 12. Multilayer structure composed of (60/40) nickel to aluminium (1st layer) and $(60 / 40+20 / 80)$ nickel to aluminium (1st and 2nd layer) and $(60 / 40+20 / 80+$ alumina) as a (1st, 2nd and 3rd layer). 


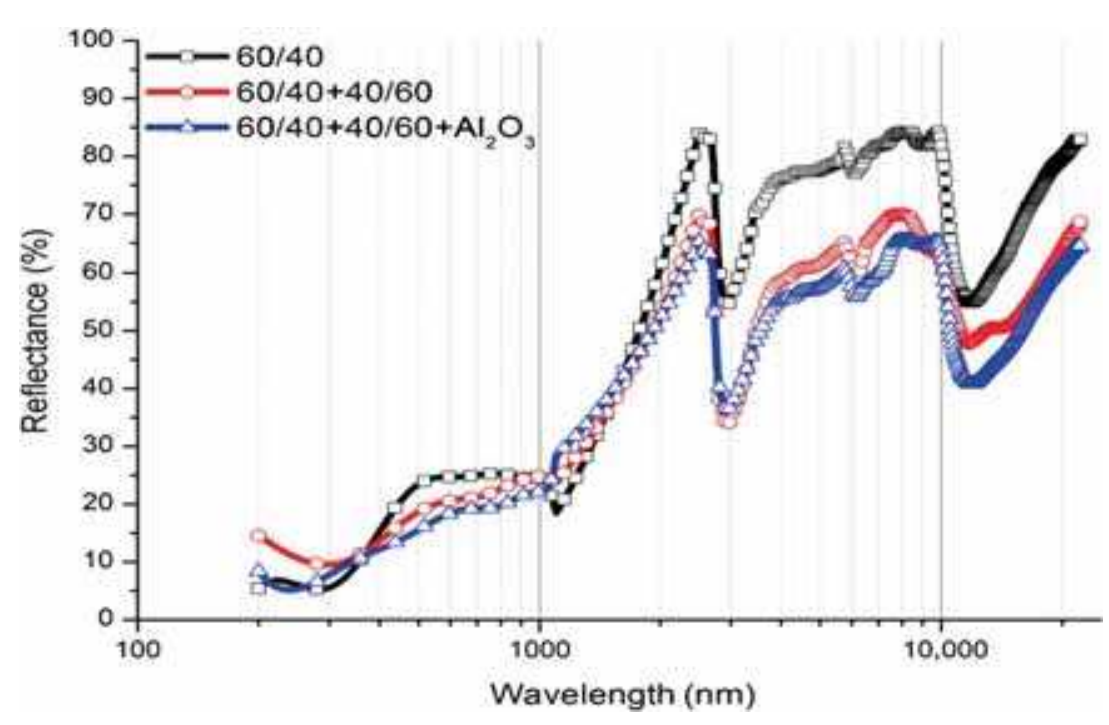

Figure 13. Multilayer structure composed of (60/40) nickel to aluminium (1st layer) and $(60 / 40+40 / 60)$ nickel to aluminium (1st and 2 nd layer) and $(60 / 40+40 / 60+$ alumina) as a (1st, 2nd and 3rd layer).

Table 4. Solar absorptance and thermal emittance of multilayer cermet.

\begin{tabular}{lccc}
\hline & $S$ & $\varepsilon_{\mathrm{t}}$ & $\alpha_{\mathrm{s}}$ \\
\hline First layer $(60 / 40)$ & 3.263 & 0.236 & 0.770 \\
First layer + second layer $(10 / 90+60 / 40+)$ & 1.967 & 0.392 & 0.732 \\
First layer + second layer + third layer $\left(60 / 40+10 / 90+\mathrm{Al}_{2} \mathrm{O}_{3}\right)$ & 2.451 & 0.328 & 0.804 \\
\hline
\end{tabular}

Table 5. Solar absorptance and thermal emittance of multilayer cermet.

\begin{tabular}{lccc}
\hline & $S$ & $\varepsilon_{\mathrm{t}}$ & $\alpha_{\mathrm{s}}$ \\
\hline First layer $(60 / 40)$ & 3.263 & 0.236 & 0.770 \\
First layer + second $(20 / 80+60 / 40+)$ & 1.864 & 0.434 & 0.809 \\
First layer + second layer + third layer $\left(60 / 40+20 / 80+\mathrm{Al}_{2} \mathrm{O}_{3}\right)$ & 2.005 & 0.421 & 0.844 \\
\hline
\end{tabular}

Table 6. Solar absorptance and thermal emittance of multilayer cermet.

\begin{tabular}{lccc}
\hline & $S$ & $\varepsilon_{\mathrm{t}}$ & $\alpha_{\mathrm{s}}$ \\
\hline First layer $(60 / 40)$ & 3.263 & 0.236 & 0.770 \\
First layer + second layer $(40 / 60+60 / 40+)$ & 1.914 & 0.428 & 0.819 \\
First layer + second layer + third layer $\left(60 / 40+40 / 60+\mathrm{Al}_{2} \mathrm{O}_{3}\right)$ & 2.046 & 0.389 & 0.796 \\
\hline
\end{tabular}

In addition to the initial efficiency, long-term stability is also an important requirement for absorber coatings [48]. Various factors such as temperature, air humidity and airborne pollutants can cause the degradation of absorbing coating and strongly affect the optical properties [49].
In principle, degradation resulting from the latter two factors can be inhibited by depositing a dense and durable protection layer on the absorbing coating. Oxidation of metallic particles and substrate diffusion at high temperature which results in optical degradation of cermet coating can also be 
inhibited by depositing a protection layer and using a suitable substrate. Other evolutions such as metallic particle size, surface roughness and adhesion at high temperature, however, strongly depend on the properties of cermet coating itself [13]. Of course, a comprehensive discussion regarding the different effective parameters on degradation mechanisms of an absorber has been proposed by Bogaerts [50].

Among various mechanisms, we selected thermal stability of the absorbing coating which determines the service lifetime of solar absorber. Generally speaking, the tandem absorbers are degraded at high operating temperatures due to their unstable microstructure, which cause a decrease in the solar selectivity [34]. At high temperatures, thermal emittance is the dominant source of losses, and the requirement of low emittance often leads to complex designs that

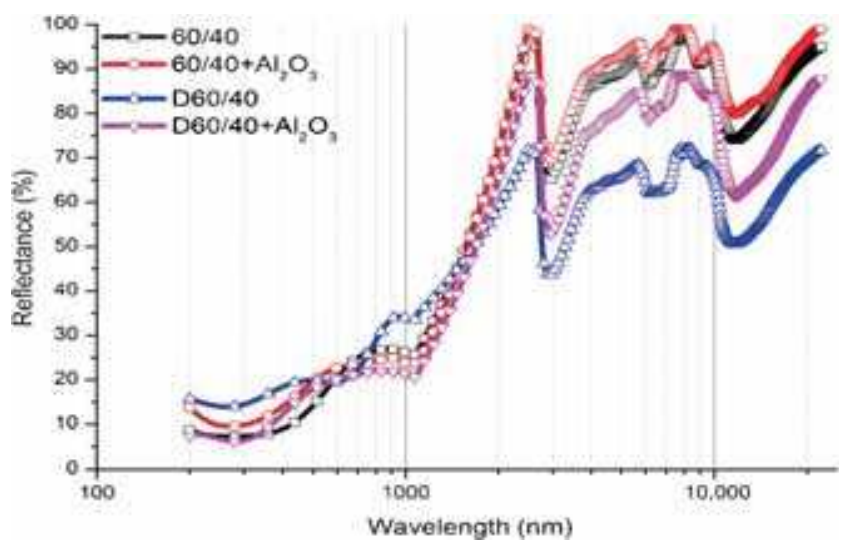

Figure 14. Thermal stability of a single and double layer of absorbing coating (prefix D means degraded sample). are frequently susceptible to degradation at the working temperature [48].

The thermal stability of coatings is assessed according to a performance criterion [49]

$$
\mathrm{PC}=-\Delta \alpha_{\mathrm{s}}+0.5 \Delta \varepsilon_{\mathrm{t}},
$$

where $\Delta \alpha_{\mathrm{s}}$ and $\Delta \varepsilon_{\mathrm{t}}$ are the differences in normal solar absorptance and in normal thermal emittance, respectively, before and after the thermal stability test. Coefficient of 0.5 is a weighting factor, which expresses the relative importance of the thermal emission compared to the solar absorptance. Often, a qualified and suitable coating requires PC smaller than 0.05 [49]. The failure time is defined as the time passing until this value reached. To reduce the annoying environmental parameters, the single layer of NiAlOx and a double layer of $\mathrm{NiAlOx}+\mathrm{Al}_{2} \mathrm{O}_{3}$ were deposited (as a protecting and antireflection layer) according to the optimized conditions, consecutively (previously described) and then the reflectance spectrum of the absorbing coatings after annealing it at $250^{\circ} \mathrm{C}$ in air for $144 \mathrm{~h}$ was tested.

The results are shown in figure 14. The PC values are estimated and given in table 7.

With a closer look, it was found that the presence of antireflection coating enhances the performance of absorber by increasing the absorptance and confines the emmitance increase which is the main source of loss. This proves that it is a good candidate for requested application as a potential solar selective absorber.

Finally, a comparison between the optimized sample and other relevant nickel-alumina-based selective absorber has been carried out. Although no similar sample that deposited by spray pyrolysis was found but comparable values are observed with other preparation methods. Table 8 summarizes the results.

Table 7. Optical properties before and after thermal stability tests for a single and double layer of absorbing coating. The performance criterion. The performance criterion (PC) after each test is also displayed.

\begin{tabular}{llllllll}
\hline & \multicolumn{2}{c}{ Before thermal stability test } & & \multicolumn{2}{c}{ After thermal stability test } & \\
\cline { 2 - 3 } Sample & $\alpha_{\mathrm{s}}$ & $\varepsilon_{\mathrm{t}}$ & & $\alpha_{\mathrm{s}}$ & $\varepsilon_{\mathrm{t}}$ & PC \\
\hline Single layer & 0.796 & 0.117 & & 0.761 & 0.362 & 0.087 \\
Double layer & 0.785 & 0.083 & & 0.807 & 0.208 & 0.040 \\
\hline
\end{tabular}

Table 8. Performance comparison between our work and some spectrally selective absorbers based on $\mathrm{Ni}_{-}-\mathrm{Al}_{2} \mathrm{O}_{3}$.

\begin{tabular}{|c|c|c|c|c|c|}
\hline Material & Substrate & Selectivity & Stability test & Preparation & Reference \\
\hline $\mathrm{Ni}-\mathrm{Al}_{2} \mathrm{O}_{3}$ & Stainless steel & 10.69 & $250^{\circ} \mathrm{C}$ in air & Spray pyrolysis & This work \\
\hline $\mathrm{Ni}-\mathrm{Al}_{2} \mathrm{O}_{3}$ & Aluminium & $15-2.1$ & $250^{\circ} \mathrm{C}$ in air & Anodization & [51] \\
\hline $\mathrm{Ni}-\mathrm{Al}_{2} \mathrm{O}_{3}$ & Fused quartz & 9.4 & $500^{\circ} \mathrm{C}$ in air & Evaporation & {$[22]$} \\
\hline $\mathrm{Ni}-\mathrm{Al}_{2} \mathrm{O}_{3}$ & Stainless steel & 13.43 & $500^{\circ} \mathrm{C}$ in air & Sputtering & {$[10]$} \\
\hline $\mathrm{Ni}-\mathrm{Al}_{2} \mathrm{O}_{3}$ & Aluminium & 18.6 & $300^{\circ} \mathrm{C}$ in air & Solution-based method & {$[13]$} \\
\hline $\mathrm{AlNi}-\mathrm{Al}_{2} \mathrm{O}_{3}$ & Stainless steel & 12.2 & $500^{\circ} \mathrm{C}$ in vacuum & Magnetron sputtering & {$[30]$} \\
\hline $\mathrm{Ni}-\mathrm{Al}_{2} \mathrm{O}_{3}$ & Aluminium & 6.29 & $300^{\circ} \mathrm{C}$ in air & Anodization & {$[52]$} \\
\hline $\mathrm{Ni}-\mathrm{Al}_{2} \mathrm{O}_{3}$ & Aluminium & $9.3-4.8$ & $300^{\circ} \mathrm{C}$ in air & Anodization + electrolysis + spray pyrolysis & {$[53]$} \\
\hline $\mathrm{Ni}-\mathrm{Al}_{2} \mathrm{O}_{3}$ & Aluminium & 4.39 & $450^{\circ} \mathrm{C}$ in air & Anodization + electrolysis + dip coating & {$[54]$} \\
\hline $\mathrm{Ni}-\mathrm{Al}_{2} \mathrm{O}_{3}$ & Aluminium & 5.81 & - & Anodization & {$[55]$} \\
\hline
\end{tabular}




\section{Conclusions}

The optical, structural and morphological properties of NiAlOx thin films deposited on stainless-steel substrates by the spray pyrolysis technique have been investigated. To find optimized substrate temperature, an intermediate nickel to aluminium ratio was chosen and the best solar absorptance $\left(\alpha_{\mathrm{s}}=0.874\right)$ was achieved at $400^{\circ} \mathrm{C}$. Then at such substrate temperature, different ratios of nickel contents were compared using reflectance spectra in UV-visible-IR regions and according to the selectivity criterion, the sample with $60 / 40$ nickel to aluminium, was significantly better than the others $(S=10.69)$. The surface investigation of the samples showed different morphologies ranging from continuous and homogeneous grains to accumulated ones with spherical or irregular shapes. XRD data revealed a combination of oxide and metallic phases of nickel and no alumina peak was observed because of its amorphous nature in this temperature region. By EDX analysis, the peaks corresponding to $\mathrm{O}, \mathrm{Al}$ and $\mathrm{Ni}$ were appeared in the spectra. However, the atomic ratio between $\mathrm{Al}$ and $\mathrm{Ni}$ was inconsistent with the initial value. A three-layer structure on SS substrate in three forms was made to obtain an AR+LMVF+HMVF structure. The best selectivity was 2.451 . In this work accelerated life testing to find out the thermal stability of the coatings by annealing at $250^{\circ} \mathrm{C}$ in air for $144 \mathrm{~h}$ was performed. The results indicated the effective role of antireflection layer for PC values by increasing the absorptance and confines the emmitance increase compared with single layer (PC decreased from 0.87 to 0.040 ).

\section{Acknowledgement}

This project was supported by the Islamic Azad University, Lahijan Branch, Iran and performed in the Physics Department of the University of Guilan.

\section{References}

[1] Nuru Z Y, Arendse C J, Muller T F, Khamlich S and Maaza M 2014 Sol. Energy Mater. Sol. Cells 120473

[2] Boström T, Valizadeh S, Lu J, Jensen J, Westin G and Wäckelgård E 2011 J. Non-Cryst. Solids 3571370

[3] Kennedy C E 2008 Progress to develop an advanced solarselective coating. In: 14th Biennial CSP Solar PACES (Solar Power and Chemical Energy Systems) Symposium 4-7 March 2008, Las Vegas, Nevada

[4] Arancibia-Bulnes C A, Estrada C A and Ruiz-Suarez J C 2000 J. Phys. D: Appl. Phys. 332489

[5] Cao F, Mc Enaney K, Chen G and Ren Z 2014 Energy Environ. Sci. 71615

[6] Gaouyat L, He Z, Colomer J-F, Lambin Ph, Mirabella F, Schryvers D and Deparis O 2014 Sol. Energy Mater. Sol. Cells 122303

[7] Reza Nejati M, Fathollahi V and Khalaji Asadi M 2005 Solar Energy 78235

[8] Wu L, Gao J, Liu Z, Liang L, Xia F and Cao H 2013 Sol. Energy Mater. Sol. Cells 114186
[9] Sathiaraj T S, Thangaraj R, Alsharbaty H and Agnihotri O P 1991 Thin Solid Films 19533

[10] Sathiaraj T S, Thangaraj R, Alsharbaty H, Bhatnagar M and Agnihotri O P 1990 Thin Solid Films 190241

[11] Davoine F, Galione P A, Ramos-Barrado J R, Leinen D, Martín F, Dalchiele E A and Marotti R E 2013 Solar Energy 91316

[12] Cuevas A, Martínez L, Romero R, Dalchiele E A, Marotti R, Leinen D, Ramos-Barrado J R and Martin F 2014 Sol. Energy Mater. Sol. Cells 130380

[13] Li Z, Zhao J and Ren L 2012 Sol. Energy Mater. Sol. Cells 10590

[14] Saxena V, Rani R U and Sharma A K 2006 Surf. Coat. Technol. 201855

[15] Shashikala A R, Sharma A K and Bhandari D R 2007 Sol. Energy Mater. Sol. Cells 91629

[16] Cindrella L 2007 Sol. Energy Mater. Sol. Cells 911898

[17] Karthick Kumar S, Suresh S, Murugesan S and Raj S P 2013 Solar Energy 94299

[18] Yin Y, McKenzie D R and McFall W D 1996 Sol. Energy Mater. Sol. Cells 4469

[19] Marquez A, Blanco G, de Rapp M E F, Lamas D G and Tarulla R 2004 Surf. Coat. Technol. 187154

[20] Ienei E, Isac L, Cazan C and Duta A 2010 Solid State Sci. 12 1894

[21] Isac L, Duta A, Purghel E, Chitanu G C, Mitrea S and Pelin I 2008 Phys. Status Solidi A 2052413

[22] Craighead H G and Buhrman R A 1977 Appl. Phys. Lett. 31423

[23] Granquist C G, Andersson A and Hunderi O 1979 Appl. Phys. Lett. 35268

[24] Sathiaraj T S, Thangaraj R and Agnihotri O P 1989 Sol. Energy Mater. Sol. Cells 18343

[25] Du X, Wang C, Wang T, Zhou L, Chen B and Ru N 2008 Thin Solid Films $\mathbf{5 1 6} 3971$

[26] Cheng J, Wang C, Wang W, Du X, Liu Y, Xue Y, Wang T and Chen B 2013 Sol. Energy Mater. Sol. Cells 109204

[27] Nuru Z Y, Arendse C J, Nemutudi R, Nemraoui O and Maaza M 2012 Physica B: Condensed Matter 4071634

[28] Yin Y, Pan Y, Hang L X, McKenzie D R and Bilek M M M 2009 Thin Solid Films 5171601

[29] Barshilia H C, Kumar P, Rajam K S and Biswas A 2011 Sol. Energy Mater. Sol. Cells $\mathbf{9 5} 1707$

[30] Xue Y, Wang C, Wang W, Liu Y, Wu Y, Ning Y and Sun Y 2013 Solar Energy 96113

[31] Antonaia A, Castaldo A, Addonizio M L and Esposito S 2010 Sol. Energy Mater. Sol. Cells 941604

[32] Sella C, Kaba A, Berthier S and Lafait J 1987 Sol. Energy Mater. Sol. Cells 16143

[33] Bagheri Khatibani A and Rozati S M 2014 Mater. Sci. Semicond. Process. 1880

[34] Setién-Fernández I, Echániz T, González-Fernández L, PérezSáez R B, Céspedes E, Sánchez-García J A, Álvarez-Fraga L, Escobar Galindo R, Albella J M, Prieto C and Tello M J 2013 Sol. Energy Mater. Sol. Cells 117390

[35] Bagheri Khatibani A and Rozati S M 2013 J. Non-Cryst. Solids 363121

[36] Ienei E, Isac L and Duta A 2010 Rev. Roum. Chim. 55161 
[37] Avila A G, Barrera E C, Huerta L A and Muhl S 2004 Sol. Energy Mater. Sol. Cells 82269

[38] Gassmann P, Franchy R and Ibach H 1994 Surf. Sci. 31995

[39] Yamada-Takamura Y, Koch F, Maier H and Bolt H 2001 Surf. Coat. Technol. 142-144 260

[40] Chryssou C E and Pitt C W 1997 Appl. Phys. A 65469

[41] Bagheri Khatibani A and Rozati S M 2015 Bull. Mater. Sci. 38319

[42] Xinkang D, Cong W, Tianmin W, Long Z, Buliang C and Ning R 2008 Thin Solid Films 5163971

[43] Deokate R J, Pawar S M, Moholkar A V, Sawant V S, Pawar C A, Bhosale C H and Rajpure K Y 2008 Appl. Surf. Sci. 254 2187

[44] Farooq M and Hutchins M G 2002 Sol. Energy Mater. Sol. Cells 7173

[45] Oe K, Toyoshima Y and Nagai H 1976 J. Non-Cryst. Solids 20405
[46] Farooq M and Lee Z H 2003 Renew. Energy 281421

[47] Zhang Q C and Mills D R 1992 J. Appl. Phys. 723013

[48] Kennedy C E 2002 Review of mid- to high-temperature solar selective absorber materials, July 2002, NREL/TP-520-31267

[49] Carlsson B, Moller K, Kohl M, Frei U and Brunold S 2000 Sol. Energy Mater. Sol. Cells 61255

[50] Bogaerts W F and Lampert C M 1983 J. Mater. Sci. 182847

[51] Kumar S N, Malhotra L K and Chopra K L 1983 Sol. Energy Mater. 7439

[52] Tesfamichael T and Roos A 1998 Sol. Energy Mater. Sol. Cells 54213

[53] Andersson A, Hunderi O and Granqvist C G $1980 \mathrm{~J}$. Appl. Phys. 51754

[54] Varol H S and Hinsch A 1996 Sol. Energy Mater. Sol. Cells 40273

[55] Suzer S, Kadirgan F, Sohmen H M, Wetherilt A J and Ture E 1998 Sol. Energy Mater. Sol. Cells 5255 